\title{
PROCEDIMENTOS PARA CONDUÇÃO DO TESTE DE FRIO EM SEMENTES DE MILHO: PRÉ RESFRIAMENTO E DISTRIBUIÇÃO DO SUBSTRATO NO INTERIOR DA CÂMARA FRIA ${ }^{1}$
}

\author{
ROSELI FÁTIMA CASEIRO ${ }^{*}$, JULIO MARCOS FILHO ${ }^{3}$
}

\begin{abstract}
RESUMO - O teste de frio realizado em laboratórios brasileiros para avaliar o vigor das sementes de milho, geralmente é conduzido em caixas plásticas de 47 x 30 x $11 \mathrm{~cm}$, utilizando como substrato, aproximadamente $16 \mathrm{~kg}$ da mistura terra e areia. A necessidade do pré-resfriamento e a disposição do substrato no interior da câmara fria constituem fatores ainda não completamente definidos para a padronização desse teste. A pesquisa foi conduzida utilizando-se amostras de sementes de milho submetidas a três tratamentos: substrato e água não resfriados (T1); água previamente resfriada a $10^{\circ} \mathrm{C}(\mathrm{T} 2)$ e substrato e água previamente resfriados a $10^{\circ} \mathrm{C}(\mathrm{T} 3)$. Ao serem colocadas na câmara fria, quatro caixas representando cada tratamento foram superpostas, formando pilhas, e outras quatro foram dispostas horizontalmente ("lado a lado"). O resfriamento do substrato, no interior da câmara fria, foi monitorado através de avaliações da temperatura 2, 4, 8 e 26 horas após a instalação do teste. De acordo com o procedimento normalmente utilizado para a condução do teste de frio, após 7 dias as caixas foram transferidas para ambiente de laboratório e, a avaliação da germinação, realizada aos 7 dias após a transferência. Os resultados indicaram que a alternativa substrato e água pré-resfriados a $10^{\circ} \mathrm{C}$, em caixas dispostas horizontalmente, confere maior uniformidade ao teste de frio para sementes de milho, produzindo resultados consistentes e próximos da padronização.
\end{abstract}

Termos para indexação: milho, vigor, teste de frio, substrato, metodologia.

\section{PROCEDURES FOR COLD TEST IN MAIZE SEEDS: PRECHILLING AND POSITION OF SUBSTRATE INSIDE THE COLD ROOM}

\begin{abstract}
The cold test for evaluating maize seed vigor is usually performed in plastic deepboxes $(47 \times 30 \times 11 \mathrm{~cm})$ filled with approximately $16 \mathrm{~kg}$ of sand/soil mixture. This study was conducted to verify the influence of prechilling the substrate in the cold test and of the arrangement of deep-boxes inside the cold room (stacked or placed side by side). These factors are not yet completely defined and contribute significantly to variations in cold test results in Brazilian seed laboratories. Maize seeds were submitted to three treatments: substrate and water without prechilling (T1); water prechilled to $10^{\circ} \mathrm{C}$ before planting (T2) and substrate and water prechilled to $10^{\circ} \mathrm{C}$ before planting (T3). Four deep-boxes of each treatment were stacked and 4 were placed side by side in the cold room. Prechilling of substrate inside the cold room was monitored by evaluating the substratum temperature at 2, 4, 8 and 26 hours after planting. After 7 days in cold chamber, the boxes were transferred to the laboratory $\left( \pm 25^{\circ} \mathrm{C}\right)$ and the germination was recorded 7 days after transfering. Results showed that the alternative "substrate and water prechilled to $10^{\circ} \mathrm{C}(\mathrm{T} 3)$ ", placed side by side, provided uniform conditions for the cold test in maize, producing more consistent results.
\end{abstract}

Index terms: cold test, Zea mays L, substrate, methodology.

\footnotetext{
${ }^{1}$ Aceito para publicação em: 02/07/2002; parte da Dissertação de Mestrado da primeira autora apresentada à USP/ESALQ.

${ }^{2}$ Pós-Graduanda do Depto. de Produção Vegetal - USP/ESALQ; bolsista
}

FAPESP; e-mail: rosecaseiro@bol.com.br

${ }^{3}$ Depto. de Produção Vegetal - USP/ESALQ, Cx. Postal 9, 13418-900, Piracicaba, SP; bolsista CNPq; e-mail: jmarcos@carpa.ciagri.usp.br 


\section{INTRODUÇÃO}

A avaliação do potencial fisiológico das sementes é fundamental como base para os processos de produção, distribuição e comercialização dos lotes de sementes. Assim, as empresas produtoras e laboratórios de análise de sementes, devem utilizar testes que ofereçam resultados reproduzíveis, confiáveis e que indiquem, com segurança, a qualidade de um lote de sementes, principalmente no que se refere ao vigor. Nesse sentido, o teste de frio é amplamente utilizado para as sementes de milho.

No Brasil, esse teste tem sido utilizado por empresas produtoras de sementes, principalmente nos estados do sul e sudeste, onde lavouras de algodão, milho e soja podem ser semeadas entre o início do mês de setembro e meados de outubro. Nesta época, é comum a ocorrência de frentes frias chuvosas, as quais, dependendo do nível de vigor dos lotes de sementes, poderão provocar sérios problemas para a germinação e emergência de plântulas (Krzyzanowski et al, 1991).

Krzyzanowski et al. (1991), Cícero \& Vieira (1994) e Dias \& Barros (1995) relataram variações da metodologia do teste de frio, embora a maioria das análises seja conduzida utilizando-se a metodologia de "terra em caixa". O método do rolo de papel, com e sem o uso de "terra", é utilizado esporadicamente e o "método da bandeja" praticamente não tem sido reconhecido no Brasil, embora seja o procedimento mais recomendado internacionalmente.

O método de "terra em caixa" encontra sérios entraves à padronização, pois requer o uso de maior quantidade de substrato, quando comparado com outros métodos. A mistura areia/terra na proporção $2: 1$ ou 3:1, geralmente é colocada em caixas plásticas $(47 \times 30 \times 11 \mathrm{~cm})$ ocupando um volume de, aproximadamente, $12.000 \mathrm{~cm}^{3}$ e peso em torno de $16 \mathrm{~kg}$. Desta forma, além da desuniformidade causada pela origem da "terra", surgem outros problemas causados pela distribuição desuniforme de água no substrato, pelo período necessário para o substrato atingir a temperatura desejada $\left(10^{\circ} \mathrm{C}\right) \mathrm{e}$, também, pelo manuseio das caixas, que apresentam peso relativamente elevado. Outra preocupação decorrente desse procedimento refere-se à disposição das caixas no interior da câmara fria; geralmente são superpostas formando pilhas e, desta forma, o resfriamento do substrato pode não ocorrer de maneira uniforme inter e intra caixas. Tais fatores podem influenciar acentuadamente a resposta das sementes ao teste de frio, colocando em dúvida a confiabilidade e reprodutibilidade do procedimento.

Outro aspecto ainda não completamente definido é a necessidade ou não do resfriamento da "terra", previamente à semeadura do teste. Procedimentos descritos pela AOSA (1983), Dias \& Barros (1995) e Hampton \& TeKrony (1995), recomendaram o resfriamento da água até $10^{\circ} \mathrm{C}$ antes da semeadura, mas não apresentaram proposta para o substrato. Por outro lado, Krzyzanowski et al., (1991) sugeriram tanto o resfriamento da água como o do substrato a $10^{\circ} \mathrm{C}$, antes da instalação do teste. A metodologia usualmente empregada em laboratórios brasileiros não prevê o pré-resfriamento da água e o do substrato.

Diante do exposto, o presente trabalho foi conduzido com o objetivo de propor alternativas para o pré-resfriamento do substrato e disposição das caixas no interior da câmara fria, visando contribuir para a uniformização do teste de frio.

\section{MATERIAL E MÉTODOS}

O presente trabalho foi conduzido no laboratório de Análise de Sementes do Departamento de Produção Vegetal, Escola Superior de Agricultura "Luiz de Queiroz" (USP/ESALQ).

\section{a) Estudo do pré-resfriamento do substrato}

Foram utilizadas oito repetições por tratamento, perfazendo 24 caixas $(47 \times 30 \times 11 \mathrm{~cm})$. Como substrato, foram utilizados aproximadamente $16 \mathrm{~kg}$ da mistura terra e areia (doravante chamada de "terra"), na proporção 3:1 (3 partes de areia para 1 parte de terra). A terra foi coletada de área anteriormente cultivada com milho. Esta etapa constou da verificação de três alternativas: "substrato não resfriado, umedecido com água a temperatura ambiente" (T1), "substrato não resfriado, umedecido com água pré-resfriada a $10^{\circ} \mathrm{C}$ " (T2) e "substrato e água pré-resfriados a $10^{\circ} \mathrm{C}$ " (T3). Para o tratamento T1, após a distribuição do substrato nas caixas, procedeu-se a semeadura e a cobertura das sementes (2 a $3 \mathrm{~cm}$ ) com o mesmo substrato. $\mathrm{O}$ fornecimento de água foi feito através do umedecimento até atingir $60 \%$ da capacidade de retenção. Esse cálculo foi feito com de acordo com as Regras para Análise de Sementes (Brasil, 1992).

O mesmo procedimento foi adotado para o tratamento $\mathrm{T} 2$, embora a água tenha sido pré-resfriada. Para o tratamento $\mathrm{T} 3$, as caixas contendo o substrato foram colocadas em câmara fria até que este atingisse a temperatura de $10^{\circ} \mathrm{C}$. Posteriormente, foram retiradas da câmara, para que se procedesse rapidamente à semeadura (o ajuste da disponibilidade de água foi feito da mesma forma descrita anteriormente, com a água previamente resfriada até $10^{\circ} \mathrm{C}$ ); após esta operação, todos os tratamentos foram reconduzidos para a câmara fria.

A comparação desses procedimentos envolveu a semeadura de duas amostras de 50 sementes por caixa; utilizou-se 
apenas um lote do cultivar AG 122 para todos os tratamentos, pois o objetivo básico era efetuar comparações entre os procedimentos adotados para o preparo do substrato.

\section{b) Estudo da disposição das caixas no interior da câmara fria}

Ao serem colocadas na câmara fria, quatro caixas (repetições), correspondentes a cada uma das três alternativas descritas anteriormente, foram dispostas horizontalmente ("lado a lado"); outras quatro foram superpostas, formando pilha. Durante a permanência no interior da câmara, foi feito o monitoramento da temperatura para identificar o período necessário para o substrato atingir $10^{\circ} \mathrm{C}$; a temperatura do substrato foi determinada com auxílio de um termômetro digital, separadamente, em cada caixa, vencidas 2 , 4, e 8 horas após a instalação do teste. Essa avaliação também foi feita para o substrato já resfriado pois, durante a semeadura, as caixas permaneceram a temperatura ambiente e, nesse intervalo de tempo, poderiam ocorrer variações da temperatura do substrato. Após 26 horas da instalação do teste, a temperatura do substrato de todas as caixas foi determinada novamente, para verificação da possível ocorrência de variações.

Após 7 dias de permanência na câmara a $10^{\circ} \mathrm{C}$, as caixas foram transferidas para laboratório (temperatura ambiente) e a avaliação da germinação realizada aos 7 dias, computando-se as porcentagens de plântulas normais correspondentes a cada tratamento.

\section{RESULTADOS E DISCUSSÃO}

Os resultados referentes à temperatura do substrato e à porcentagem de plântulas normais, após o resfriamento, obtidos durante o estudo sobre pré-resfriamento do substrato e disposição das caixas no interior da câmara fria, encontram-se nas figuras 1 a 6 .

Como o substrato, em todos os tratamentos, não havia atingido $10^{\circ} \mathrm{C}$ após 8 horas de avaliação, a temperatura foi determinada novamente após 26 horas, para verificar se havia atingido a temperatura desejada e, também, para detectar possíveis variações dos resultados.
Durante as primeiras horas de resfriamento, verificou-se estratificação de temperatura do substrato, tanto nos tratamentos em que o umedecimento foi realizado com água à temperatura ambiente (figura 1) como pré-resfriada a $10^{\circ} \mathrm{C}$ (figura 2), ambos em caixas empilhadas. Como exemplo, 4 horas após a instalação, a temperatura das caixas superior (1) e inferior (4) era inferior às das determinadas nas caixas centrais ( $2 \mathrm{e}$ 3). Entretanto, no primeiro caso (água à temperatura ambiente), as diferenças de temperatura foram ainda maiores. Estes dois tratamentos, também apresentaram diferenças acentua-

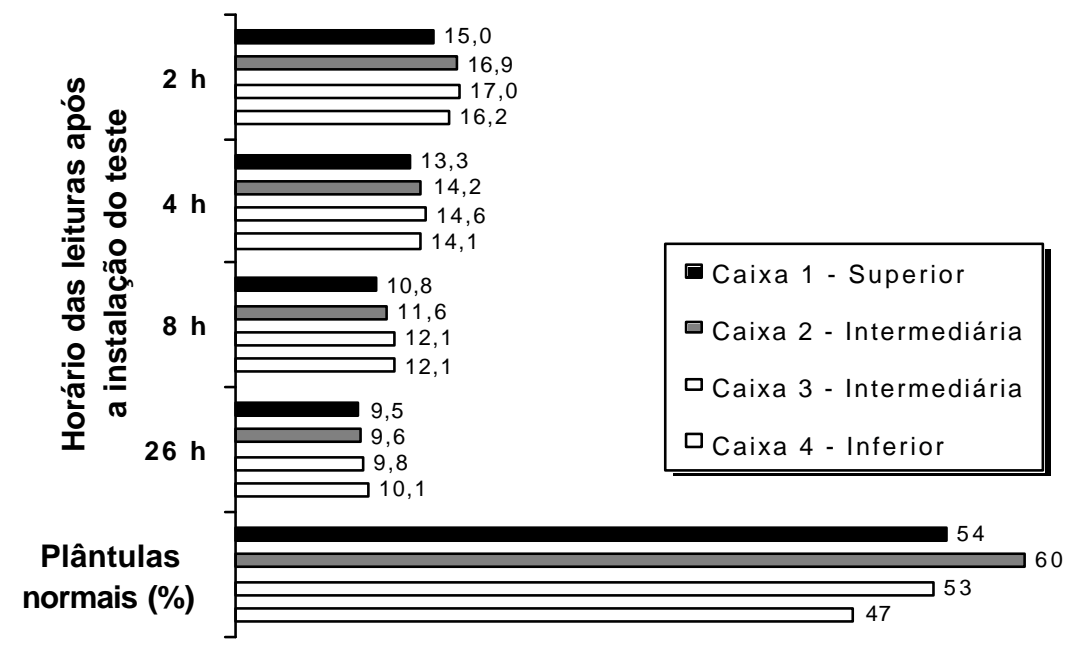

FIG. 2. Teste de frio: temperaturas do substrato $\left({ }^{\circ} \mathrm{C}\right)$, obtidas em 4 períodos de leitura após a instalação do teste, e porcentagens de plântulas normais, referentes ao tratamento "substrato sem pré-resfriamento, umedecido com água resfriada a $10^{\circ} \mathrm{C}$ ", em caixas empilhadas.

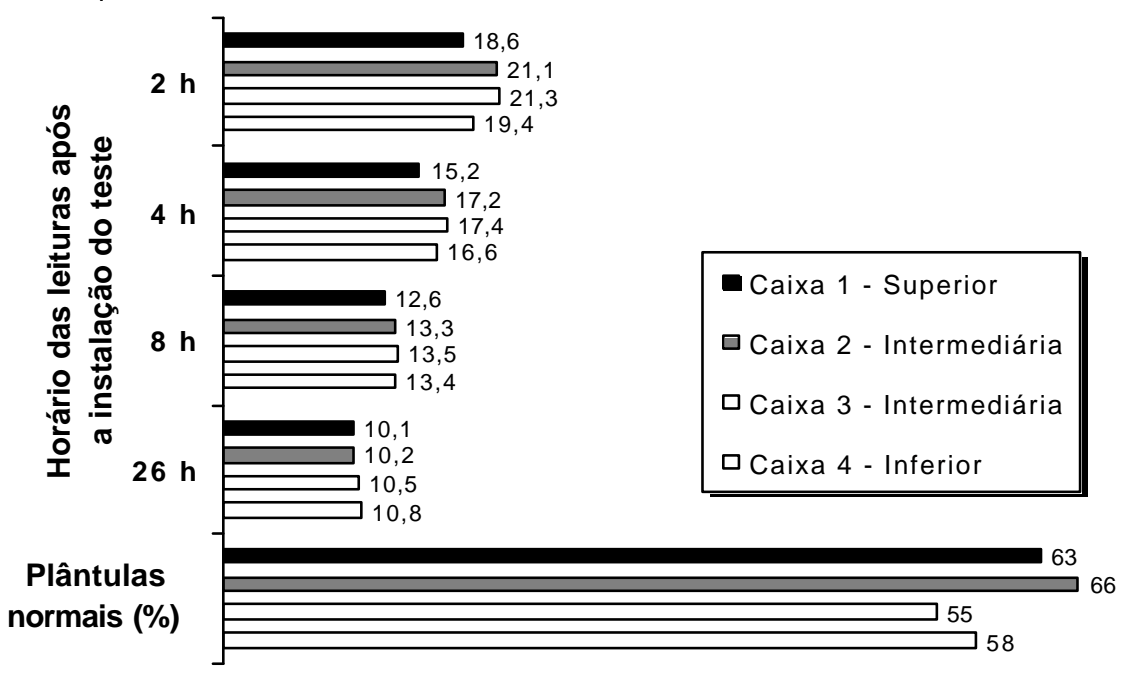

FIG. 1. Teste de frio: temperaturas do substrato $\left({ }^{\circ} \mathrm{C}\right)$, obtidas em 4 períodos de leitura após a instalação do teste, e porcentagens de plântulas normais, referentes ao tratamento "substrato sem pré-resfriamento, umedecido com água a temperatura ambiente”, em caixas empilhadas. 
das na porcentagem de plântulas normais, entre as 4 caixas da pilha (figuras 1 e 2).

Posteriormente, nas avaliações realizadas 8 e 26 horas após a instalação do teste, foram verificadas diferenças mais amplas de temperatura do substrato, entre as caixas 1 (superior) e 4 (inferior), permanecendo esta com temperatura ligeiramente mais elevada.

Como o ar frio circula livremente pelas laterais e, também, pela superfície das caixas posicionadas na parte superior da pilha, o resfriamento do substrato ocorreu de forma mais rápida nesse local. Nas caixas de posição intermediária e inferior, o resfriamento ocorreu mais lentamente. Provavelmente, a caixa situada na parte superior (caixa1) atua como barreira, dificultando a passagem de ar através do substrato; esta dificuldade deve determinar menor velocidade de resfriamento de caixas situadas na posição central da pilha (nesta pesquisa, caixas 2 e 3). Portanto, o resfriamento das caixas intermediárias e da caixa inferior deve ocorrer, principalmente, a partir das faces laterais de cada uma delas.

Apesar de haver redução da circulação de ar na superfície do substrato da caixa inferior, verificou-se que o resfriamento ocorreu mais rapidamente em relação ao verificado para as caixas intermediárias. A hipótese mais provável para esse fato indica que o ar frio tende a se acumular em regiões mais próximas ao piso da câmara. Assim, esse efeito foi pronunciado durante as primeiras horas de resfriamento, notando-se que, posteriormente, o substrato da caixa inferior (caixa 4) manteve temperatura semelhante à das demais caixas.

No tratamento "substrato e água resfriados a $10^{\circ} \mathrm{C}$ ", em caixas empilhadas (figura 3 ), verificou-se estratificação menos acentuada da temperatura; novamente, apenas o substrato da caixa 1 (superior) apresentouse com temperatura mais baixa. Neste caso, considerando-se o conjunto das 4 caixas, o resfriamento do substrato e a porcentagem de plântulas normais foram mais uniformes, quando comparados aos outros dois tratamentos referentes a caixas empilhadas (figuras 1 e 2); observou-se também, resfriamento mais rápido do substrato.
Quando os tratamentos "substrato sem pré-resfriamento, umedecido com água a temperatura ambiente" (figura 4), "substrato sem pré-resfriamento, umedecido com água préresfriada a $10^{\circ} \mathrm{C}$ " (figura 5) e "substrato e água pré-resfriados a $10^{\circ} \mathrm{C}$ " (figura 6), corresponderam à disposição das caixas lado a lado, as variações temperatura do substrato nas diferentes caixas foram acentuadamente menores; o teste também tornou-se mais drástico, o que pôde ser observado pelo grau de redução na porcentagem de plântulas normais para

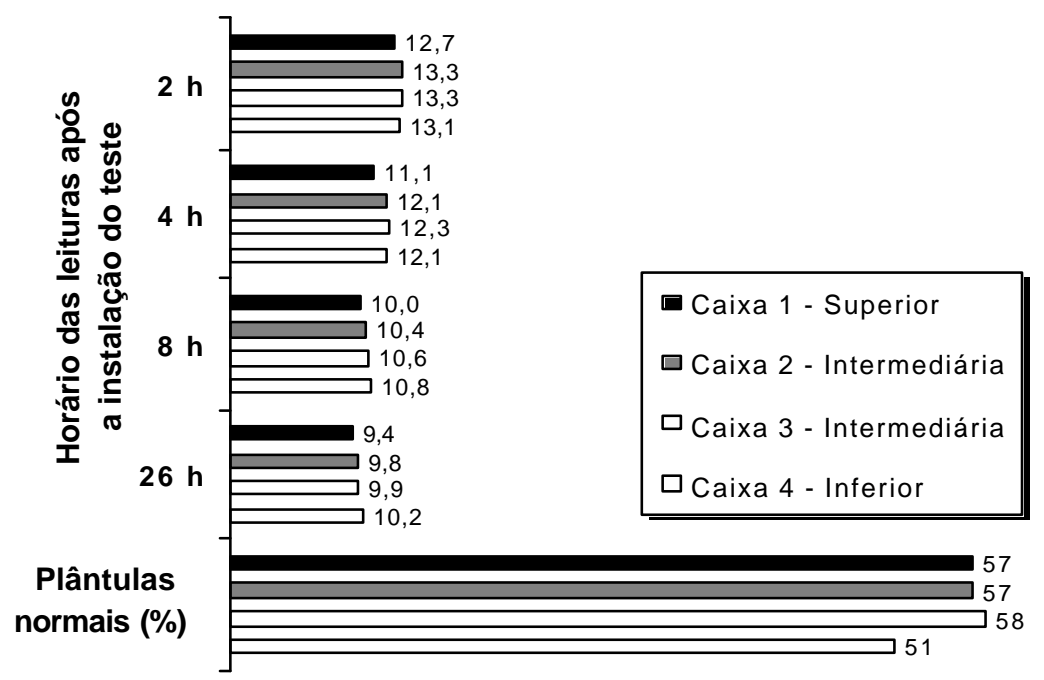

FIG. 3. Teste de frio: temperaturas do substrato $\left({ }^{\circ} \mathrm{C}\right)$, obtidas em 4 períodos de leitura após a instalação do teste, e porcentagens de plântulas normais, referentes ao tratamento "substrato e água pré-resfriados a $10^{\circ} \mathrm{C}$ ', em caixas empilhadas.

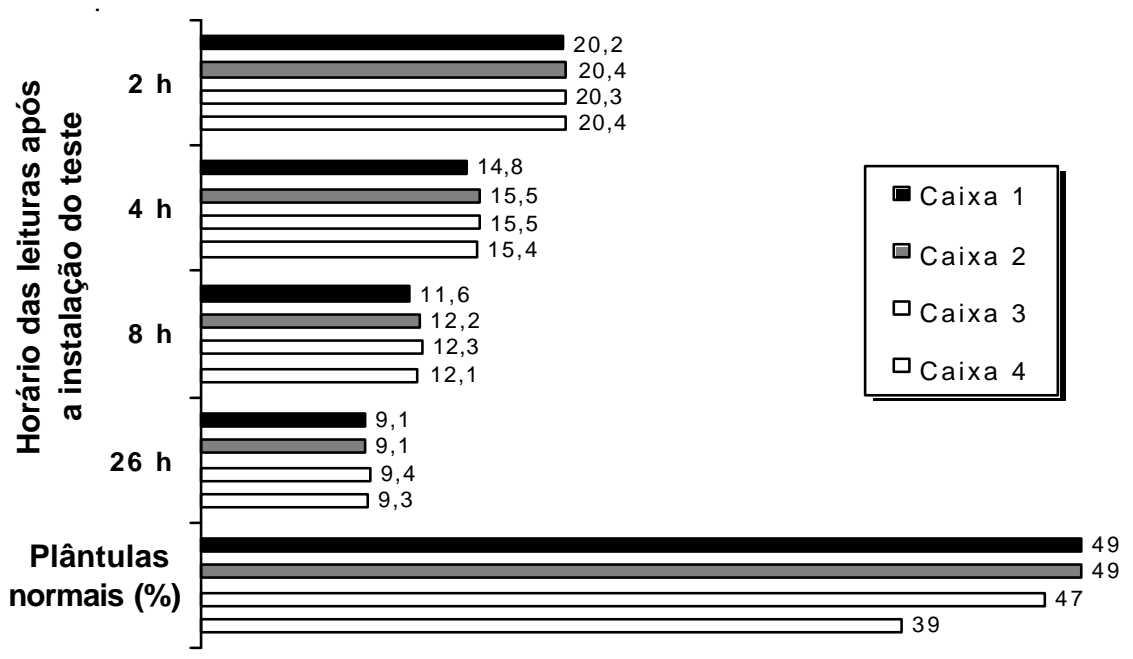

FIG. 4. Teste de frio: temperaturas do substrato $\left({ }^{\circ} \mathrm{C}\right)$, obtidas em 4 períodos de leitura após a instalação do teste, e porcentagens de plântulas normais, referentes ao tratamento "substrato sem pré-resfriamento, umedecido com água a temperatura ambiente", em caixas dispostas lado a lado. 


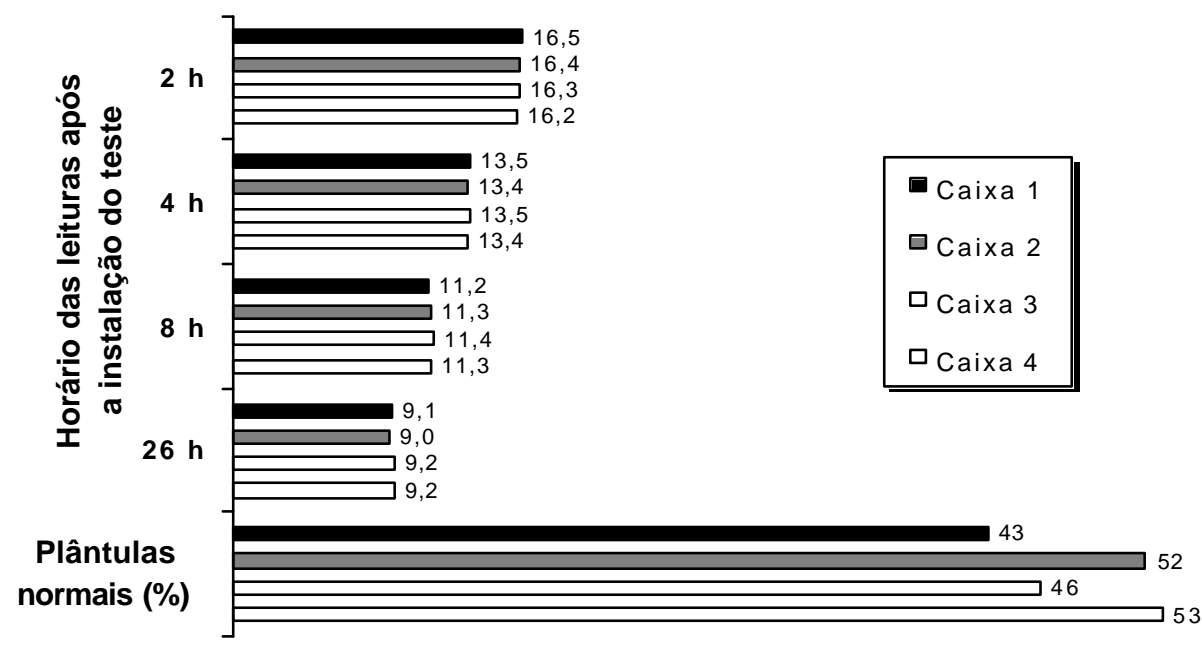

FIG. 5. Teste de frio: temperaturas do substrato $\left({ }^{\circ} \mathrm{C}\right)$, obtidas em 4 períodos de leitura após a instalação do teste, e porcentagens de plântulas normais, referentes ao tratamento "substrato sem pré-resfriamento, umedecido com água resfriada a $10^{\circ} \mathrm{C}$ ", em caixas dispostas lado a lado.

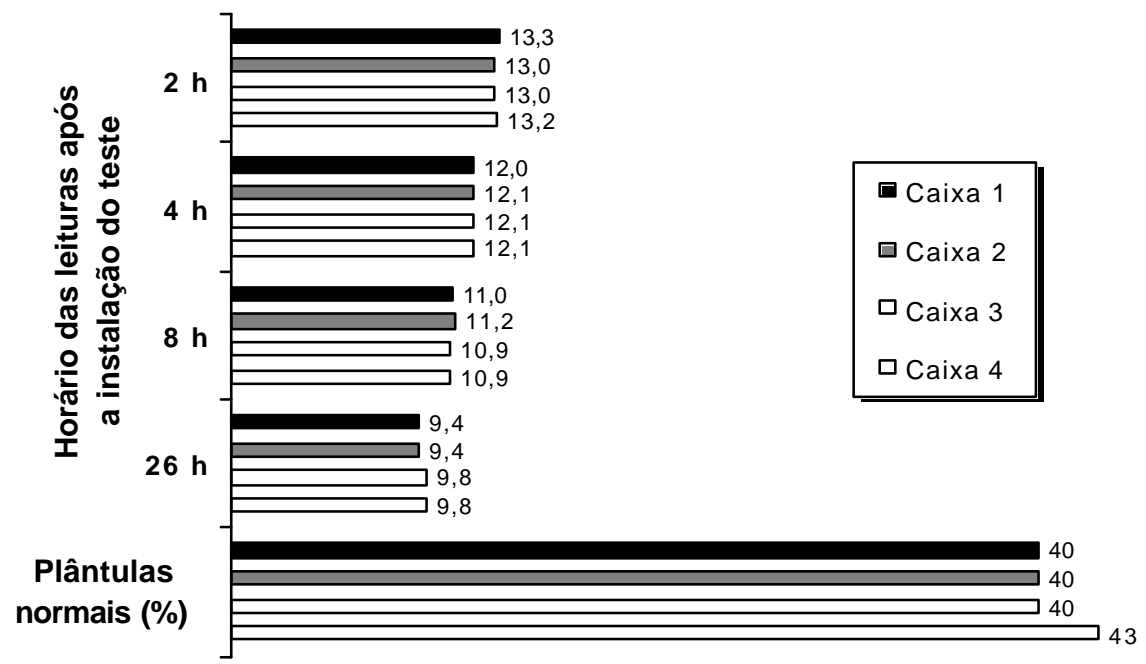

FIG. 6. Teste de frio: temperaturas do substrato $\left({ }^{\circ} \mathrm{C}\right)$, obtidas em 4 períodos de leitura após a instalação do teste, e porcentagens de plântulas normais, referentes ao tratamento "substrato e água pré-resfriados a $10^{\circ} \mathrm{C}$ ", em caixas dispostas lado a lado.

todos os tratamentos. Nos dois primeiros casos (figuras $4 \mathrm{e}$ 5), o resfriamento do substrato ocorreu de maneira uniforme e mais rapidamente, quando comparado com os mesmos tratamentos em caixas empilhadas. Porém, neste caso (figuras 4 e 5), também houve variações na porcentagem de plântulas normais entre as caixas do mesmo tratamento. No entanto, para o tratamento "substrato e água pré-resfriados a $10^{\circ} \mathrm{C}$ " em caixas dispostas lado a lado (figura 6), apesar da maior uniformidade de temperatura do substrato e da porcentagem de plântulas normais, notou-se praticamente a mesma veloci- dade de resfriamento, quando comparado com o mesmo tratamento em caixas empilhadas.

Em todos os tratamentos realizados, não foi possível identificar exatamente o período necessário para o substrato atingir $10^{\circ} \mathrm{C}$. Porém, destaca-se que, após 26 horas da instalação do teste, o tratamento envolvendo substrato sem préresfriamento umedecido com água a temperatura ambiente, em caixas empilhadas (figura 1), ainda não havia atingido $10^{\circ} \mathrm{C}$.

Como o resfriamento do substrato não ocorreu de maneira uniforme no sistema de caixas empilhadas, a embebição das sementes ocorreu sob diferentes condições de temperatura. Destaque-se, ainda, que a fase de embebição ocorreu sob influência de temperaturas superiores à preconizada para o teste de frio $\left(10^{\circ} \mathrm{C}\right)$. Tais fatos, certamente constituíram fontes adicionais de variação dos resultados obtidos no presente trabalho.

As injúrias por resfriamento são mais severas quando a queda da temperatura ocorre durante o início da embebição (Woodstock \& Pollock, 1965; Pollock \& Toole, 1966; Christiansen, 1968; Cal \& Obendorf, 1972). Quando a embebição tem início sob temperaturas favoráveis (em torno de $25^{\circ} \mathrm{C}$ ), as sementes ficam menos sensíveis aos danos causados pelo frio, mesmo que sejam expostas a baixas temperaturas no decorrer do processo de germinação. Woodstock \& Pollock (1965) verificaram que temperaturas de $15^{\circ} \mathrm{C}$ ou inferiores, durante as primeiras horas de embebição, inibiram o crescimento das plântulas de feijão lima (Phaseolus lunatus L.). Cal \& Obendorf (1972) destacaram que a injúria pode ocorrer durante a embebição, porém é mais pronunciada com o prolongamento do período de frio.

Embora o teste de frio envolvendo substrato e água préresfriados (T3), em caixas dispostas "lado a lado" (figura 6), tenha favorecido a obtenção de maior uniformidade da temperatura durante o resfriamento do substrato e, consequentemente, da porcentagem de plântulas normais, também apre- 
sentou desvantagens. Assim, a adoção desse procedimento requer mais espaço no interior da câmara fria e exige o préresfriamento do substrato, fato também que prolonga ainda mais o período de realização do teste. Portanto, em laboratórios onde o teste de frio é adotado como análise de rotina, a utilização desse procedimento provocaria obstáculos para o setor de controle de qualidade.

De qualquer forma, para se verificar a eficiência desses procedimentos na classificação dos lotes em diferentes níveis de vigor, foi necessário que os mesmos fossem comparados com outras metodologias do teste de frio, bem como com outros testes de vigor freqüentemente utilizados na avaliação da qualidade das sementes de milho. Essas informações estão disponíveis em Caseiro \& Marcos Filho (2000), que constataram que, apesar dos inconvenientes já citados, o teste de frio em caixas dispostas horizontalmente, com o préresfriamento da água e do substrato, apresentou a mesma eficiência na classificação de lotes que outros dois métodos do teste de frio conduzidos em bandejas; este último procedimento (em bandejas), teve a vantagem de ocupar menos espaço no interior da câmara fria e de utilizar quantidades menores de substrato ( 1 ou $2 \mathrm{~kg}$ ), oferecendo maior facilidade para a condução do teste e obtenção de resultados mais consistentes. O teste de frio em caixas empilhadas, sem o préresfriamento da água e do substrato, apresentou deficiências na separação dos lotes em diferentes níveis de vigor, especialmente para o cultivar AG 3010.

Considerando os dados obtidos no presente trabalho, verificou-se que, de maneira geral, o procedimento habitualmente utilizado no Brasil para a condução do teste de frio, envolvendo a utilização de substrato sem pré-resfriamento umedecido com água a temperatura ambiente (T1), em caixas empilhadas (figura 1), não demonstrou ser eficiente. Este procedimento contribui para a estratificação da temperatura do substrato entre as diferentes caixas e, também, maior desuniformidade na porcentagem de plântulas normais. Ain$\mathrm{da}$, de acordo com pesquisa realizada por Caseiro \& Marcos Filho (2000), este método mostrou falhas em distinguir lotes com potencial fisiológico distinto. Segundo Marcos Filho (1999), é necessário diferenciar nitidamente os lotes de alto dos de baixo potencial fisiológico, para não agravar as possibilidades de prejuízos ao produtor e ao consumidor. Outro ponto a ser destacado é que, por utilizar quantidade de "terra" relativamente elevada (aproximadamente $16 \mathrm{~kg}$ ), este procedimento apresentou maiores dificuldades tanto na condução quanto na padronização do teste.

\section{CONCLUSÕES}

Es A interpretação dos resultados obtidos nesta pesquisa permitiu concluir que, a alternativa substrato e água pré-resfriados a $10^{\circ} \mathrm{C}$, em caixas dispostas horizontalmente "lado a lado", sobre o piso da câmara fria, confere maior uniformidade ao teste de frio para sementes de milho, produzindo resultados mais consistentes que os obtidos com o uso do procedimento tradicionalmente empregado em laboratórios de sementes, em diferentes regiões do Brasil.

\section{REFERÊNCIAS}

ASSOCIATION OF OFFICIAL SEED ANALYSTS. Seed vigor testing handbook. 88p. 1983. Contrib. $\mathrm{n}^{\circ} 32$ to the Handbook on Seed Testing.

BRASIL. Ministério da Agricultura e da Reforma Agrária. Regras para análise de sementes. Brasília: SNDA/DNDV/CLAV, 1992. $365 \mathrm{p}$.

CAL, J.P.; OBENDORF, R.L. Imbibitional chilling injury in Zea mays L. altered by initial kernel moisture and maternal parent. Crop Science, Madison, v.12, p.369-373, May/June, 1972.

CASEIRO, R.F.; MARCOS-FILHO, J. Métodos alternativos do teste de frio para a avaliação do vigor de sementes de milho. Scientia Agricola, Piracicaba, v.57, n.3, p.459-466, 2000.

CHRISTIANSEN, M.N. Induction and prevention of chilling injury to radicle tips of imbibing cottonseed. PlantPhysiology, Rockvilles, v.43, p.743-746, 1968.

CÍCERO, S.M.; VIEIRA, R.D. Teste de frio. In: VIEIRA, R.D.; CARVALHO, N.M. (Ed.). Testes de vigor em sementes. Jaboticabal: FUNEP, 1994. p.151-164.

DIAS, M.C.L.L.; BARROS, A.S.R. Avaliação da qualidade de sementes de milho. Londrina: IAPAR, 1995. 43p. (IAPAR. Circular, 88).

HAMPTON, J.G; TEKRONY, D.M. Handbook of vigour test methods . 3.ed. Zurich: International Seed Testing Association, 1995. $117 \mathrm{p}$.

KRZYZANOWSKI, F.C.; FRANÇA NETO, J.B.; HENNING A.A. Relato dos testes de vigor disponíveis para grandes culturas. Informativo ABRATES, Londrina, v.1, n.2, p.15-50, 1991.

MARCOS-FILHO, J. Testes de vigor: importância e utilização. In: KRZYZANOWSKI, F.C.; VIEIRA, R.D.; FRANÇA NETO, J.B. Vigor de sementes: conceitos e testes. Londrina: ABRATES, 1999. p.1-1 - 1-21.

POLLOCK, B.M.; TOOLE, V.K. Imbibitional period as the critical temperature sensitive stage in germination of lima bean seeds. Plant Physiology, Minneapolis, v.41, p.221-229, 1966.

WOODSTOCK, L.W.; POLLOCK, B.M. Physiological predetermination: imbibition, respiration, and growth of lima bean seeds. Science, v.150, p.1031-1032, 1965.

\section{Let}

